\title{
A pilot study of the nutritional status of disabled and non- disabled children living in Rajkot, Gujarat
}

\author{
Rina Rensiya and Hemangi D. Mehta
}

\begin{abstract}
It is recognized that disabled children living in poverty are among the most deprived in the world. However, there is limited data regarding their nutritional status. Feeding difficulties contributing to poor nutrition have been reported among disabled children living in more affluent environments. Studies in developing countries are complicated by widespread malnutrition among the general population and by a lack of appropriate means of assessing nutritional status. United National guidelines for anthropometric assessment of nutritional status do not provide sufficient information to enable health workers to identify malnutrition among disabled children in the community. The present study found no evidence to suggest that the disabled child may be an additional drain on scarce family resources. Height-for-age was significantly lower in disabled than non-disabled children. It is difficult to determine accurate height among physically impaired children and thus, the present study may have over-estimated the prevalence of stunting among disabled children. The study clearly shows a lack of variety in the diet.
\end{abstract}

Key Words : Disabled children, Nutritional status, Non-disabled childrenn, Nutritional status

How to cite this article : Rensiya, Rina and Mehta, Hemangi D. (2017). A pilot study of the nutritional status of disabled and nondisabled children living in Rajkot, Gujarat. Food Sci. Res. J., 8(2): 219-222, DOI : 10.15740/HAS/FSRJ/8.2/219-222.

Email : hemangidmehta@gmail.com 